\title{
Optical Emission Spectrometer
}

National Cancer Institute

\section{Source}

National Cancer Institute. Optical Emission Spectrometer. NCI Thesaurus. Code C62339.

An emission spectrometer that generates a high-energy spark across an argon-filled gap between an electrode and a solid sample, causing emission of radiation from the excited sample surface and resulting in wavelengths characteristic of the elemental composition. 